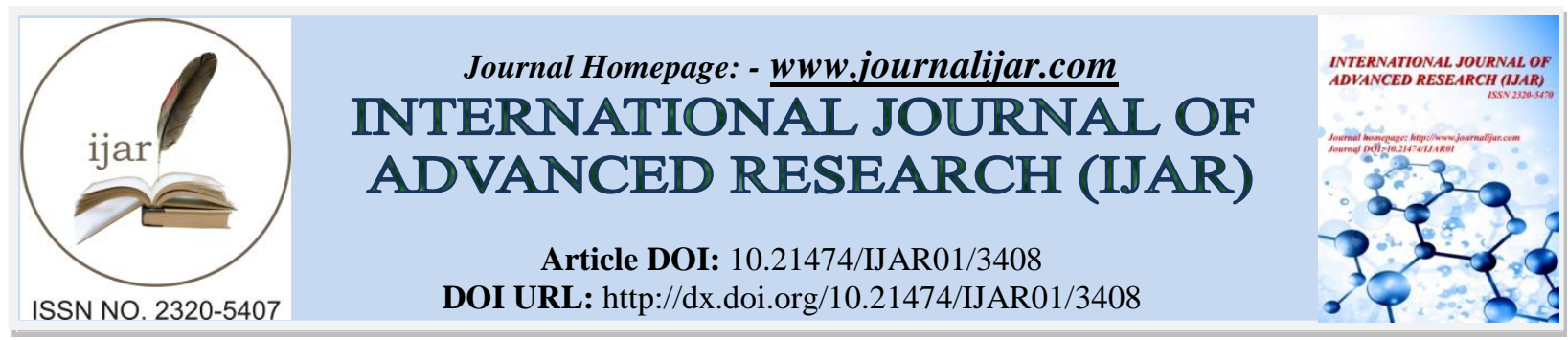

RESEARCH ARTICLE

ENERGY MANAGEMENT.

Gaikwad Karan Prabhakar and Devkar Sanchita Dattatray.

Manuscript Info

Manuscript History

Received: 17 December 2016

Final Accepted: 22 January 2017

Published: February 2017

\begin{abstract}
Energy consumes maximum cost in manufacturing so its management is important aspect which should be studied. Energy management deals with planning, organizing and implementation of energy resources to get maximum productivity. Energy management function should be integrated with organizational culture so as to attain cost effective utilization of resources. Energy conservation is an important part in eco-friendly production and defines ethics of organization towards environment. Energy audit process is carried out these days to study use and utilization of energy. Maintaining energy balance is principle which must be followed while managing energy. Technical and economic feasibility of energy should be studied while implementing projects so that cost effective utilization of resources can be possible. Global resource utilization can only bepossible through managing and conserving energy reserves.
\end{abstract}

Copy Right, IJAR, 2017,. All rights reserved.

\title{
Research Methodology:-
}

The data used for research is secondary data obtained from publications, reports, and surveys by government, private and international organizations. The research is Descriptive, Exploratory and explanatory in nature for study of various dimensions related to energy and its management.

\section{Objectives:-}

○ To study national and global energy consumption

- To study role of energy management function in an organization

- To study energy conservation techniques and methods

- To study energy audit method

- To study energy balance and its importance

- To study importance of integrating energy management function with organizational culture for global energy conservation.

- To study economic and technical feasibility of energy in manufacturing and production management process.

\section{Introduction:-}

Energy management deals with planning and operation of energy production and energy consumption units. As conservation of energy is becoming a global issue of concern it is important need to integrate energy management function with organizational structure so that energy management techniques can be developed and implemented properly. The central task of energy management in an organization is to reduce costs for the provision of energy in buildings and facilities without compromising work processes. Energy prices fluctuate constantly which can significantly affect energy bills in an organization. Poor energy procurement decisions costs organization a high 
loss. Organization can control and reduce energy costs by taking a proactive and efficient approach in buying energy. Even a change in energy can be a profitable and eco-friendly alternative.

\section{Energy Consumption:-}

Sector wise Energy Consumption Pattern

\begin{tabular}{|c|c|c|c|}
\hline Sectors & International Level & National Level & State Level \\
\hline Industry & $51.7 \%$ & $29 \%$ & $25 \%$ \\
\hline Transport & $26.6 \%$ & $30 \%$ & $0.6 \%$ \\
\hline Domestic & $13.9 \%$ & $27 \%$ & $49 \%$ \\
\hline Commercial & $7.8 \%$ & $9 \%$ & $17 \%$ \\
\hline Others & 0 & $5 \%$ & $8.4 \%$ \\
\hline
\end{tabular}

(Source: World Energy Outlook 2014)

The main reasons for higher specific energy consumption in Indian industries are:

\section{energy consumption}

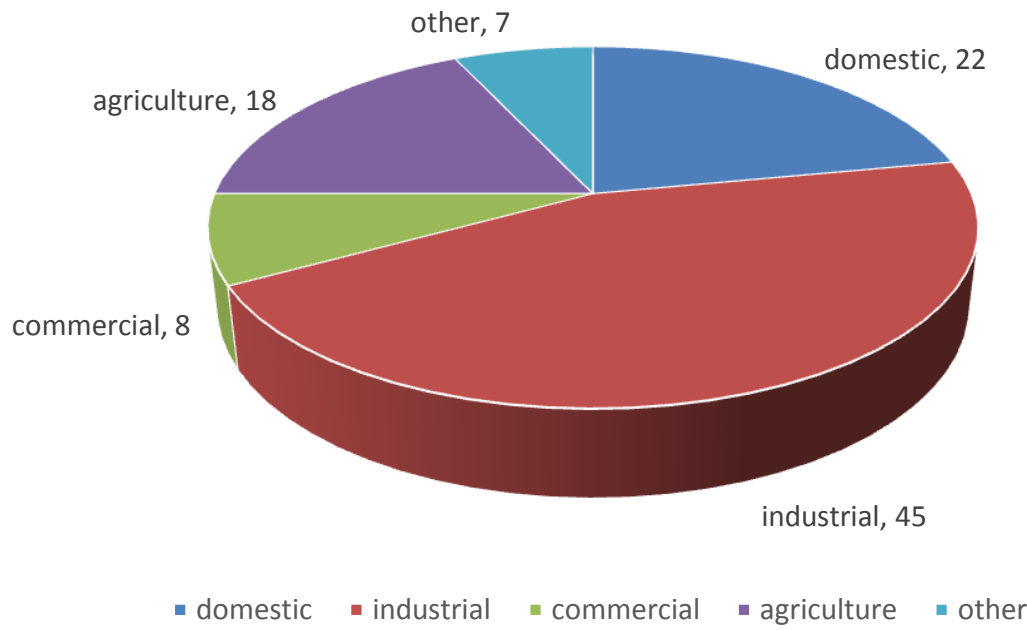

- Obsolete technology

- Lower capacity utilization

- Causal metering and monitoring of energy consumption

- Lower automation

- Raw material quality and poor handling

- Operating and maintenance practices

- Lack of knowledge/awareness among the employees

\section{Energy procurement:-}

\section{Eliminate Waste:-}

Ensure that energy is used at the highest possible efficiency.

\section{Maximize Efficiency:-}

Utilize the most appropriate technology to meet organizational needs. Optimize Supply: Purchase or supply energy at the lowest possible cost. Energy management practices may vary from simple maintenance and operational activities that ensure equipment and systems use energy efficiently and effectively, to capital intensive installation of new, more efficient technology.

\section{Energy audit:-}

Energy audit is an inspection, analysis and survey of energy flows energy for buildings, process or system. The audit process starts by collecting information about a facility's operation and about its past record of utility bills. This data 
is then analyzed to get a picture of how the facility uses and possibly wastes energy, as well as to help the auditor learn what areas to examine to reduce.In any industry the top most three expenses are on energy whether its energy, labour and material.

If one were to relate cost which can be manageable or potential cost of savings in each of the above components, energy would be invariable top ranker in cost and thus energy management function constitutes a strategic area for cost reduction. The energy audit would give a positive orientation towards cost reduction, preventive maintainance and quality control.

\section{Dimensions of energy Audit:-}

○ energy as a system - to study natural role, laws and use of energy for its judicious use and energy resource utilisation.

- Conversion- It accounts for energy input, storage, conversion,waste, sales and consumption.

- Statistics measurement- measures instruments, calibration, measuring rate, and instrumentmanagement. This also includes the scope of energy report, frequency ofsubmission, breakdown level, depth of analysis, etc.

o indicators of energy consumptions - it accounts for a company's energy consumption, butnot its energy inputs.

O Operating efficiency - operating techniques and its efficiency in production process.

- Energy consumption during manufacturing - includes consumption per unit ofoutput value, per unit of product, direct and indirect energy consumption and energyconsumption per comparable unit product.

○ Energy cost indicators - multiplies energy consumption by energy price.

o Energy savings techniques and methods- differentiates actual energy consumption and benchmarkconsumption. Setting energy usage standards and its implementing procedures.

- Economic analysis of energy-saving projects - makes a comparative analysis ofEnergy economic costs for similar products and conditions. Analysis of energy feasibility of project.

\section{Identification of Energy Conservation Opportunities:-}

○ Fuel substitution: Identifying the appropriate fuel for efficient energy conversion, finding substitutes for rare and costly fuels and energy sources.

○ Energy generation :Identifying Efficiency opportunities in energy conversion equipment/utility such as captive power generation, steam generation in boilers, thermic fluid heating, optimal loading of DG sets, minimum excess air combustion with boilers/thermic fluid heating, optimizing existing efficiencies, efficientenergy conversion equipment, biomass gasifiers, Cogeneration, high efficiency DG sets, etc.

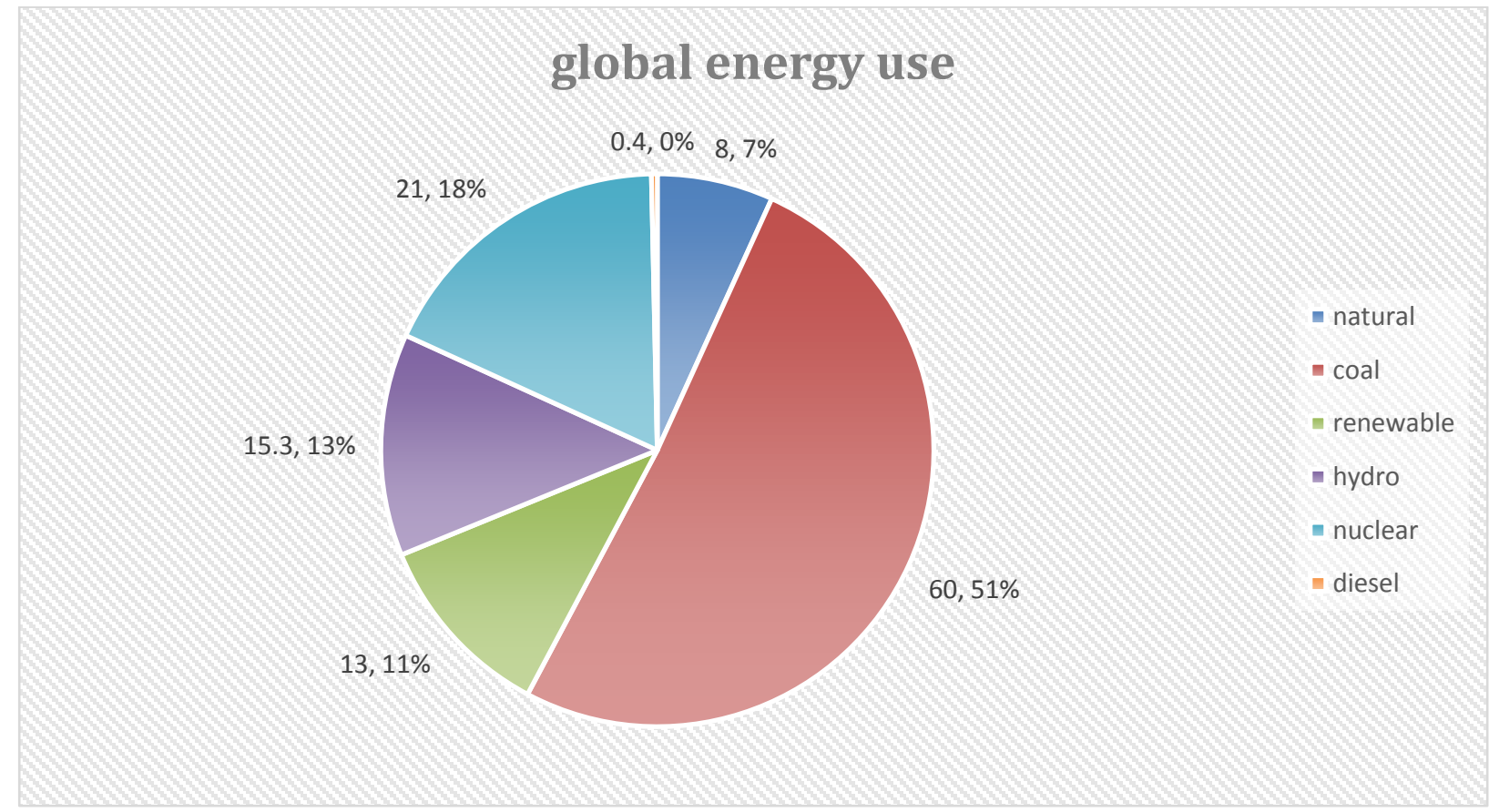


○ Energy distribution and supply management: Identifying Efficiency opportunities network such as transformers, cables, switchgears and power factor improvement in electrical systems and chilled water, cooling water, hot water, compressed air, Etc.

○ Energy usage by processes: This is where the major opportunity for improvement and many of them are hidden. Process analysis is useful tool for process integration measures.

$\circ$ Technical and Economic feasibility

The technical feasibility should address the following issues:-

1. Technology availability, space, skilled manpower, reliability, service etc

2. The impact of energy efficiency measure on safety, quality, production or process.

3. The maintenance requirements and spares availability

It is observed that $25 \%$ of energy cost can be saved if energy management techniques are applied in various manufacturing and production functions.

- Logistics: it is an important factor of energy consumption as transport of goods and products requires large consumption of fuels.

- Supply chain management: if proper supply chain management techniques are applied wastage of energy can be prevented.

- Production planning and control: planning organizing and directing energy resources towards cost effective production techniques.

- Material Management: adequate procurement and storage of material if implied properly can utilize energy and prevents its over use.

\section{Findings:-}

- Increasing energy consumption is felt throughout globe in recent years of industrialization.

- Energy management function is gaining popularity in organization due to its key task of cost reduction.

- Energy conservation is must for eco-friendly production and manufacturing process.

- Energy audit and energy inspection techniques are necessary for cost effective production.

- There should be integrating of energy management function with organizational culture for global energy conservation.

- The economic and technical feasibility plays important aspect of energy conservation and cost reduction in manufacturing and production industries.

- Energy balance: it studies amount of energy used by a site or unit, its supply and its utilization. It deals with how much amount of energy is supplied or used and how much should be supplied or consumed

\section{Conclusion:-}

Global energy scarcity is issue of concern that's why energy conservation and energy management has got prime important in many countries. For Cost effective production and manufacturing, energy management function should be implemented in organizational culture. Energy audit is an investigative and analytical part of energy management which is gaining popularity. Ethical standards should be implemented to control overall energy consumption in organization. Maintaining energy balance is must to utilize energy resources in standard and gain maximum profit. Technical and economic feasibility should be studied while implementing manufacturing techniques and production processes. Global resource utilization is possible only if energy reserves are managed properly.

\section{References:-}

1. Energy Statistics 2016 Central Statistics Office Ministry Of Statistics And Programme Implementation Government Of India New Delhi.

2. Energy Management Handbook Sixth Edition.

3. IJAREEIE, Vol. 4, Issue 2, February 2015 A Review On Energy Management And Audit By Anupama Gupta, Pallaviverma And Richa Priyadarshani.

4. Energy Efficiency In India History And Overview By Reshmivasudevan, Dr. Koshy Cherail C, Dr. Ramesh Bhatia And Nisha Jayaram.

5. BSR Energy Management Handbook. 